\title{
INDUÇÃO DE FITOALEXINAS EM SOJA E SORGO POR PREPARAÇÕES DE SACCHAROMYCES BOULARDII
}

\author{
J.R. Stangarlin ${ }^{1 *}$, D.G. Schulz ${ }^{1}$, G. Franzener ${ }^{1}$, L. Assi ${ }^{1}$, K.R.F. Schwan-Estrada ${ }^{2}$, O.J. Kuhn ${ }^{3}$ \\ ${ }^{1}$ Universidade Estadual do Oeste do Paraná, Centro de Ciências Agrárias, CP 91, CEP 85.960-000, Marechal \\ Cândido Rondon, PR, Brasil. E-mail: jrstangarlin@pq.cnpq.br
}

RESUMO

O gênero Saccharomyces tem sido usado como indutor de resistência ou para controle biológico em muitos patossistemas. Neste trabalho objetivou-se a indução de fitoalexinas em mesocótilos de sorgo e cotilédones de soja pela levedura Saccharomyces boulardii na forma do produto comercial Floratil (Merck) (com 2 × $10^{6}$ células/mg produto comercial - pc) e massa de células obtidas de meio líquido YEPG (primeiramente com 14 dias de cultivo e, posteriormente, com 7, 14, 21, 28 e 35 dias) ambos em concentrações de 0,$005 ; 0,05 ; 0,5 ; 5 ; 15$ e $25 \mathrm{mg} / \mathrm{mL}$, além de filtrado desse meio nas concentrações de 0,$01 ; 0,1 ; 1 ; 5 ; 10$ e 20\%. Como tratamentos controle utilizou-se água e $S$. cerevisiae (25 mg/mL de pc) para soja e água e acibenzolar-S-metil (ASM) (125 mg i.a./L) para sorgo. Em soja os três produtos apresentaram efeito dose-dependente, com ajustes de equações de $1^{\circ}$ grau e $\mathrm{R}^{2}$ de 0,64; 0,94 e 0,98 não tendo efeito do tempo de cultivo da levedura na indução de fitoalexinas. Em sorgo apenas o filtrado e Floratil tiveram efeito dose-dependente com equação de $1^{\circ}$ grau e $\mathrm{R}^{2}$ de 0,63 e 0,94 respectivamente e obteve-se nos diferentes dias de cultivo $R^{2}$ de 0,62 com a massa de células somente. Portanto, pode-se evidenciar o potencial indutor de fitoalexinas dos produtos a base de S. boulardii para ensaios com indução de resistência em patossistemas envolvendo sorgo e soja.

PALAVRAS-CHAVE: Gliceolina, deoxiantocianidinas, levedura.

\section{ABSTRACT}

INDUCTION OF PHYTOALEXINS IN SOYBEAN AND SORGHUM BY SACCHAROMYCES BOULARDII. Saccharomyces yeast compounds have been used as a resistance elicitor or for biological control in many pathosystems. Thus, the aim of this research was to verify the induction of phytoalexins in sorghum mesocotyls and soybean cotyledons by using Saccharomyces boulardii in the form of the commercial product Floratil (Merck) (with $2 \times 106$ cells $/ \mathrm{mg}$ ) and yeast-cell mass obtained from liquid culture in YEPG medium (with 7, 14, 21, 28 and 35 days old), both at concentrations of $0.005,0.05,0.5,5,15$ and $25 \mathrm{mg} / \mathrm{mL}$, as well as the filtrate of this medium in concentrations of $0.01,0.1,1,5,10$ and $20 \%$. The control treatments consisted of distilled water and S. cerevisiae ( $25 \mathrm{mg}$ of commercial product per $\mathrm{mL}$ ) for the soybean tests and distilled water and acibenzolar-S-methyl (125 mg of active ingredient per L) for the sorghum tests. In soybeans the three tested S. boulardii products presented a dose-dependent effect with R2 of 0.64, 0.94 and 0.98 for the culture filtrate, cell suspension and commercial product of $S$. boulardii, respectively, with no effect of culture time of yeasts on phytoalexin induction. In sorghum, only the culture filtrate and Floratil presented a dose-dependent effect, with R2 of 0.63 and 0.94, respectively, and the cell suspension of $S$. boulardii showed dependence of culture time with R2 of 0.62 . Thus, S. boulardii and its derivates induce phytoalexins and have potential to be used as an elicitor for assays with induction resistance in pathosystems involving sorghum and soybean plants.

KEY WORDS: Glyceollin, deoxyanthocyanidins, yeasts.

\section{INTRODUÇÃO}

O controle químico de doenças de plantas, mesmo quandoutilizadodeformaadequada, podecausaruma série de problemas, como desequilíbrio ecológico pela ação sobre organismos não alvos, seleção de isolados dos patógenos insensíveis a esses produtos químicos, alem deafetara saúdedas pessoas (GHINI; KIMATI, 2000).

\footnotetext{
${ }^{2}$ Universidade Estadual de Maringá, Maringá, PR, Brasil. ${ }^{3}$ Universidade Federal do Pampa, Itaqui, RS, Brasil.

*Bolsistas do CNPq.
} 
Muitos produtores já estão utilizando com sucesso outros métodos para controle de fitopatógenos, como cultural, biológico e físico. Outros a té aboliram o controle químico, desenvolvendo a agricultura orgânica, alguns por consciência ecológica, outros, porém, simplesmente com o objetivo de explorar novos nichos de mercado que eventualmente venha lhe proporcionar maior lucratividade (STANGARLIN et al., 2008). Visando minimizar esses efeitos negativos e aumentar a produção de alimentos de melhor qualidade, propiciando assim o desenvolvimento de uma agricultura alternativa e/ ou sustentável, têm-se buscado novas medidas de proteção das plantas contra as doenças (Popia et al.,2007). Neste chamado controle alternativo inserem-se o controlebiológico, a indução de resistência em plantas (MORAEs, 1992) e o uso de extratos naturais com propriedades antimicrobianas e ou indutoras de resistência (STANGARLIN et al., 2008).

Ocontrolebiológico podeser definido como o controle de um micro-organismo antagônico, o qual pode atuar por meio de antibiose, parasitismo, competição, predação ou hipovirulência (COOK; BAKER, 1983).

A indução da resistência envolve a ativação de mecanismos de defesa latentes existentes nas plantas em resposta ao tratamento com agentes bióticos (como micro-organismos viáveis ou inativados)(STANGARLIN; Pascholati, 1994) ou abióticos, como acibenzolar-Smetil (OsswALD et al., 2004), além de metais pesados, luz ultravioleta, ácido salicílico, fosfitos e silicatos, entre outros (CAVALCANTI et al., 2005). Esses mecanismos de resistência podem incluir o acúmulo de fitoalexinas e de proteínas relacionadas à patogênese como $\beta-1,3$ glucanases, quitinases e peroxidases (SchWAN-Estrada et al., 2008). Moléculas de origem biótica ou abiótica, capazes de ativar/induzir qualquer resposta de defesa nas plantas, são chamadas de elicitores ou eliciadores. Entre os elicitores não convencionais podem-se incluir os extratos de plantas medicinais e óleos essenciais (compostos secundários) com propriedades antimicrobianas e/ou indutoras de resistência (STANGARLIN et al., 1999; SCHWAN-ESTRADA; STANGARLIN, 2005), bem como os extratos obtidos de cogumelos (Di PIERO et al., 2005; VIECELLietal.,2009) e deleveduras como Saccharomyces cerevisiae (PICcinin et al., 2005).

Vários micro-organismos são eficazes e promissores na proteção de plantas contra infecções fúngicas (CAlvoetal.,2003; El-TARABILY;SivasithamParam, 2006). Por possuírem múltiplos mecanismos de ação, tais como parasitismo, antibiose ou produção de antibióticos, produção deenzimas hidrolíticas extracelulares, ação sobre fatores de patogenicidade, competição e indução de resistência, as leveduras vêm recebendo cada vez mais atenção (GouveA et al.,2007). Na década de 70 demonstrou-se que o fungo unicelular $S$. cerevisiae, utilizado em panificação e para produção de etanol, apresentava elicitores na parede celular (PAscholati, 1998). Isso, aliado à facilidade de cultivo dessa levedura em laboratório ou da aquisição no mercado (fermento comercial), estimulou pesquisas com ouso desta levedura para controle de doenças em plantas (PUNJA; UTKHEDE, 2003).

Suspensões de células e outras preparações obtidas a partir de S. cerevisiae são capazes de protegerem plantas de café contra Hemileia vastatrix (ferrugem do cafeeiro). Para o cultivar de cafeeiro Mundo Novo, MARTINset al. (1986) verificaram que o filtrado proporcionou controle da doença, o que envolveu a indução de resistência, pois não houve efeito direto sobre a germinação deuredósporoseformação deapressórios pelopatógeno.

Em plantas desorgo, o tratamento com S. cerevisiae, formulado como Fermento Biológico Fleishmann ${ }^{\circledR}$, protegeu parcialmente o cultivar Brandes em casa de vegetação (dose de $1 \mathrm{mg} / \mathrm{mL}$ ) e no campo (dose de 5 $\mathrm{mg} / \mathrm{mL}$ ) contra Colletotrichum sublineolum (LoPEZ, 1991). A levedura reduziu significativamente a germinação de conídios do patógeno e nas plantas tratadas houve acúmulo de compostos fenólicos.

Além das suspensões de células de $S$. cerevisiae, o filtrado decultivo da levedura inibiu a germinação de esporos e a formação de apressórios de C. graminicola e protegeu plantas de milho contra o patógeno(SILVA; Pascholati, 1992). Ainda em plantas de milho, a proteção conferida por S. cerevisiae contra Exserohilum turcicum envolveu redução no tamanho e no número de lesões por planta, na esporulação do fungo nos tecidos do hospedeiro, além da inibição da germinação e da penetração dos conídios. A resposta protetora foi dependente da concentração da levedura utilizada, bem como do intervalo de tempo entre a aplicação da levedura e a inoculação das plantas, e envolveu antibiose e indução de resistência (STANGARLIN; PASCHOLATI, 1994).

A levedura S. boulardii, isolada de frutas silvestres tropicais, pode ser encontrada na forma liofilizada no medicamento Floratil ${ }^{\circledR}$ (Merck) na concentração de 2 x $10^{6}$ células/mg. Oprodutoéutilizado comoauxiliar na restauração da flora intestinal e possui antagonismo a Escherichia coli, Shigella sp., Salmonella sp., Pseudomonas sp., Staphylococcus sp. e Candida albicans (Merck, 2007). Ao contrário de S. cerevisiae, até o momento não há relatos do uso de $S$. boulardii para controle de doenças em plantas, tanto por atividade antimicrobiana direta quanto por ativação de mecanismos de defesa vegetal, como as fitoalexinas.

As fitoalexinas são definidas como compostos antimicrobianos de baixa massa molecular, sintetizadas e acumuladas nas plantas após estresses físicos, químicos ou biológicos, como o contato com microorganismos, e seu papel na resistência a patógenos é amplamente estudado, sendo capaz de reduzir ou 
impedir a atividade de agentes patogênicos (BRAGA, 2008). Mais de 300 fitoalexinas já foram caracterizadas entre diferentes classes de compostos químicos como cumarina, diterpeno eflavonoide, entre outras, tendo sido identificadas em mais de 20 famílias de vegetais superiores. Em sorgo, são conhecidas quatro fitoalexinas (flavonóides 3-deoxiantocianidinas): luteolinidina, 5-metoxiluteolinidina, apigeninidina eéster doácido cafêico dearabinisol5-o-apigeninidina (Nicholson et al., 1988). No caso da soja a fitoalexina gliceolina (pterocarpanoide) mostra-se importante na interação dessa leguminosa com fitopatógenos (BURDEN; BAILEY, 1975).

Bioensaios com mesocótilos estiolados de sorgo e com cotilédones de soja são ferramentas importantes para se testar o efeito elicitor de um tratamento (Stangarlin et al.,1999). WulfF; Pascholati (1998), em estudos com $S$. cerevisiae na atividade elicitora de fitoalexinas em mesocótilos de sorgo, obtiveram resultados positivos, demonstrando que os mesocótilos tratados apresentaram pigmentação característica da síntese de fitoalexinas.

Dessa forma, os objetivos deste trabalho foram avaliar o potencial elicitor de fitoalexinas em mesocótilos de sorgo e cotilédones de soja, pelo filtrado de cultura, suspensão de células e produto comercial a base de Saccharomyces boulardii, utilizando-se diferentes concentrações e tempos de cultivo.

\section{MATERIALEMÉTODOS}

\section{Obtenção de células de $S$. boulardii}

Células de $S$. boulardii foram obtidas a partir do produto comercial Floratil (Merck). Para tanto, 100 $\mathrm{mg}$ do produto foram colocados em $100 \mathrm{~mL}$ de água destilada esterilizada e, a partir dessa suspensão, foi feito o isolamento em meio de cultivo YEPG sólido e incubação no escuro a $36^{\circ} \mathrm{C}$.

\section{Obtenção de filtrado de cultura de S. boulardii}

S. boulardii isolada foi repicada para meio líquido YEPG e mantida em agitação (150 rpm) e escuro a $36^{\circ}$ C. Foram utilizados frascos erlenmeyers de $250 \mathrm{~mL}$ contendo $100 \mathrm{~mL}$ de meio de cultivo, que foi autoclavado a $110^{\circ} \mathrm{Ce} 1 \mathrm{~atm}$ por $15 \mathrm{~min}$. Cada frasco recebeu $100 \mu \mathrm{L}$ de suspensão de células (obtida do meio sólido com $48 \mathrm{~h}$ de incubação) contendo $1 \times 10^{5}$ células / $\mathrm{mL}$. Após sete dias, os meios foram filtrados assepticamente em papel Whatman $n^{\circ} 41$, obtendo-se, dessa forma, o filtrado bruto da cultura eas células da levedura. O filtrado obtido foi mantido em geladeira a $4^{\circ} \mathrm{C}$, enquanto que as células da levedura foram utilizadas imediatamente nos ensaios.
Efeito do tempo de cultivo de $S$. boulardii na indução de fitoalexinas

Os frascos com meio YEPG líquido e células de $S$. boulardii foram mantidos em constante agitação em agitador orbital(150 rpm) por 35 dias, períodono qual os filtrados e células foram obtidos em diferentes tempos, aos 7, 14, 21, 28 e 35 dias de cultivo. Esses filtrados e células foram utilizados nos ensaios de indução de fitoalexinas em cotilédones de soja e mesocótilos de sorgo.

Efeito de concentrações de filtrado e células de $S$. boulardii na indução de fitoalexinas

Os filtrados foram utilizados nas concentrações de 0,$01 ; 0,1 ; 1 ; 5 ; 10$; e 20\%, enquanto que as células foram utilizadas nas concentrações de 0,$005 ; 0,05 ; 0,5$; $5 ; 15$ e $25 \mathrm{mg} / \mathrm{mL}$. Também foi utilizado o produto comercial Floratil ${ }^{\circledR}$ nas concentrações de 0,$005 ; 0,05$; 0,$5 ; 5 ; 15 \mathrm{e} 25 \mathrm{mg} / \mathrm{mL}$. Essas diferentes concentrações foram utilizadas nos ensaios de indução de fitoalexinas em cotilédones de soja e mesocótilos de sorgo.

\section{Bioensaio para produção de fitoalexinas em mesocótilos de sorgo}

Sementes de sorgo [Sorghum bicolor (L.) Moench], cultivar Brandes, foram desinfestadas em hipoclorito de sódio $1 \%$, por 15 min elavadas em água destilada. Após esse período, foram enroladas em folhas de papel de germinação umedecidas e incubadas em escuro a $28^{\circ} \mathrm{C}$ por quatro dias. Em seguida, as plântulas formadas foram inicialmente expostas à luz por 4h para paralisar a elongação dos mesocótilos. Para o teste de produção de fitoalexinas, os mesocótilos foram excisados $0,5 \mathrm{~cm}$ acima do nó escutelar e colocados em tubos para microcentrífuga (três/mesocótilos por tubo), contendo uma alíquota de $1 \mathrm{~mL}$ de extrato bruto (EB) ou filtrado de cultura nas concentrações citadas anteriormente. Como testemunha negativa foi utilizada água destilada esterilizada e como positiva o acibenzolar-S-metil (125 mg do ingrediente ativo/L) (Osswald etal., 2004). Os tubos foram mantidos em câmara úmida, $\mathrm{a} 25^{\circ} \mathrm{C}$, sob luz fluorescente, por $60 \mathrm{~h}$. Após esse período, os mesocótilos foram retirados dos tubos e os $0,5 \mathrm{~mm}$ basais de cada mesocótilo foram descartados. A porção superior $(2,5 \mathrm{~cm})$ foi pesada, cortada em pequenos segmentos e colocada em novos tubos contendo $1,4 \mathrm{~mL}$ de metanol $80 \%$ acidificado $(0,1 \%$ $\mathrm{HCl} ; \mathrm{v} / \mathrm{v})$. Os mesocótilos cortados foram mantidos a $4^{\circ} \mathrm{C}$ no metanol por $96 \mathrm{~h}$, para extração dos pigmentos. A absorbância foi determinada a $480 \mathrm{~nm}$ (Nicholson et al., 1988). 
Bioensaio para produção de fitoalexinas em cotilédones de soja

Sementes de soja (Glycinemax L.), cultivar BRS134 (Vigoet al.,2001), foram desinfestadas em hipoclorito desódio por 10 min esemeadas em bandejas contendo areia autoclavada (três vezes à temperatura de $121^{\circ} \mathrm{C}$ e $1 \mathrm{~atm})$. As bandejas foram colocadas em casa de vegetação por 10 dias, sendo em seguida destacados os cotilédones para execução do bioensaio.

Os cotilédones destacados foram colocados em placas de Petri (seis cotilédones/placa) contendo três folhas de papel de filtro esterilizadas e umedecidas em água destilada esterilizada. Em cada cotilédone foi feita uma "cunha" na superfície adaxial, com o auxílio de um estilete e, em cada uma destas, foram adicionados $20 \mu \mathrm{L}$ dos tratamentos. As placas ficaram incubadas em $\mathrm{BOD}$, à temperatura de $25^{\circ} \mathrm{C}$, no escuro, por 20h. Após esse período, os cotilédones foram transferidos para erlenmeyers de $125 \mathrm{~mL}$ com $15 \mathrm{~mL}$ de água destilada esterilizada e esses foram agitados em agitador orbital (150 rpm) durante $1 \mathrm{~h}$, para extração dos pigmentos. Em seguida, os cotilédones foram retirados e o sobrenadante foi lido em espectrofotômetro com absorbância de $285 \mathrm{~nm}$. Como testemunha negativa foi utilizada água destilada esterilizada e como positiva suspensão de células de $S$. cerevisiae $(20 \mathrm{mg} / \mathrm{mL}$ do produto comercial Fermento Biológico Fresco Fleishmann) (Meinerz et al., 2008).

\section{RESULTADOSEDISCUSSÃO}

Em soja, os três produtos com sete dias de cultivo apresentaram efeito dose-dependente (Fig. 1), com ajustes de equações de $1^{\circ}$ grau e $R^{2}$ de 0,$64 ; 0,94$ e 0,98 para filtrado, massa de células e Floratil, respectivamente. $\mathrm{O}$ melhor efeito indutor foi com massa de células $(20 \mathrm{mg} / \mathrm{mL})$, seguido de Floratil $(20 \mathrm{mg} / \mathrm{mL})$, com valores $37 \%$ e $23 \%$ maiores que o tratamento com S. cerevisiae. Para filtrado, a maior indução foi para a concentração de $20 \%$, com valor, no entanto, semelhanteao obtido com o tratamento controle positivo(S. cerevisiae).

O fato do tratamento com massa de células de $S$. boulardii ter proporcionado o mesmo efeito indutor queFloratil indica que essa induçãoé provavelmente devidoaos componentes da célula da levedura, enão aos adjuvantes presentes no produto comercial.

Quando testados os diferentes dias de cultivo de S. boulardii $(7,14,21,28$ e 35 dias) não se obteve influência dos mesmos na indução de gliceolina tanto para o filtrado de cultura quanto para a massa de células, sendo esses valores semelhantes ao controle negativoágua (Fig.2). Para o tratamento com Floratil, cuja suspensão de células liofilizadas foi obtida apenas no momento da aplicação nos cotilédones, tendo, portanto, células de S. boulardii em início de atividade metabólica, a indução para produção de gliceolina foi $94 \%$ maior que o tratamento com S. cerevisiae e $394 \%$ maior que o tratamento com água.

\section{FILTRADO}

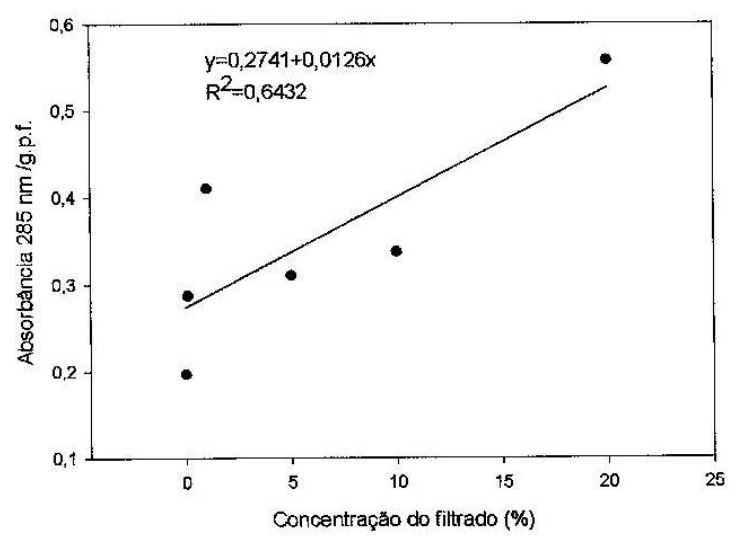

S. boulardii

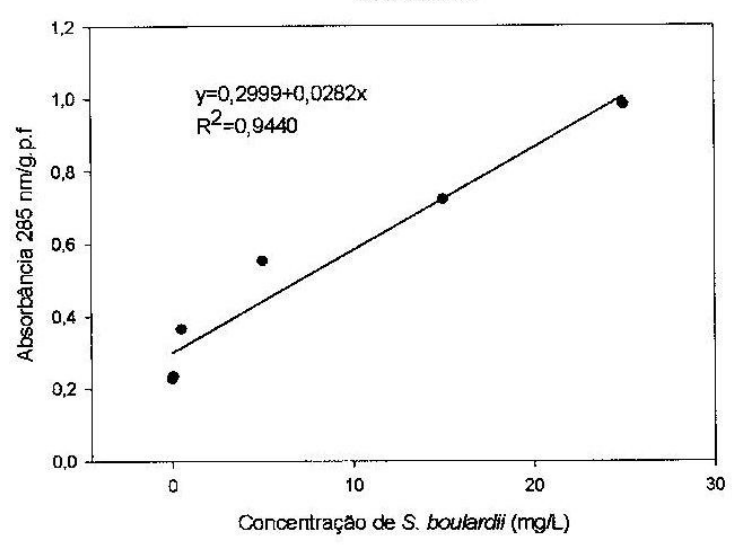

PRODUTO FLORATIL

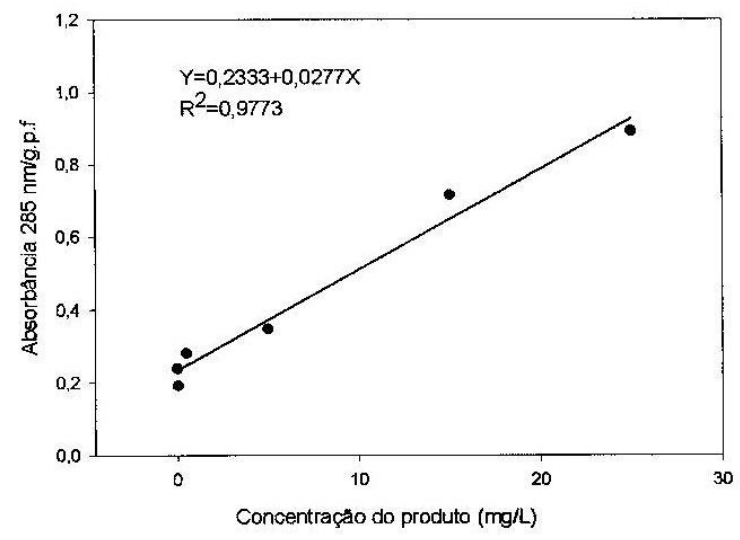

Fig. 1 - Produção de fitoalexinas em cotilédones de soja submetidos ao tratamento com filtrado de cultura e suspensão de células de Saccharomyces boulardii e produto comercial Floratil. S. boulardii foi cultivada em meio YEPG; g.p.f .= grama de massa fresca. 

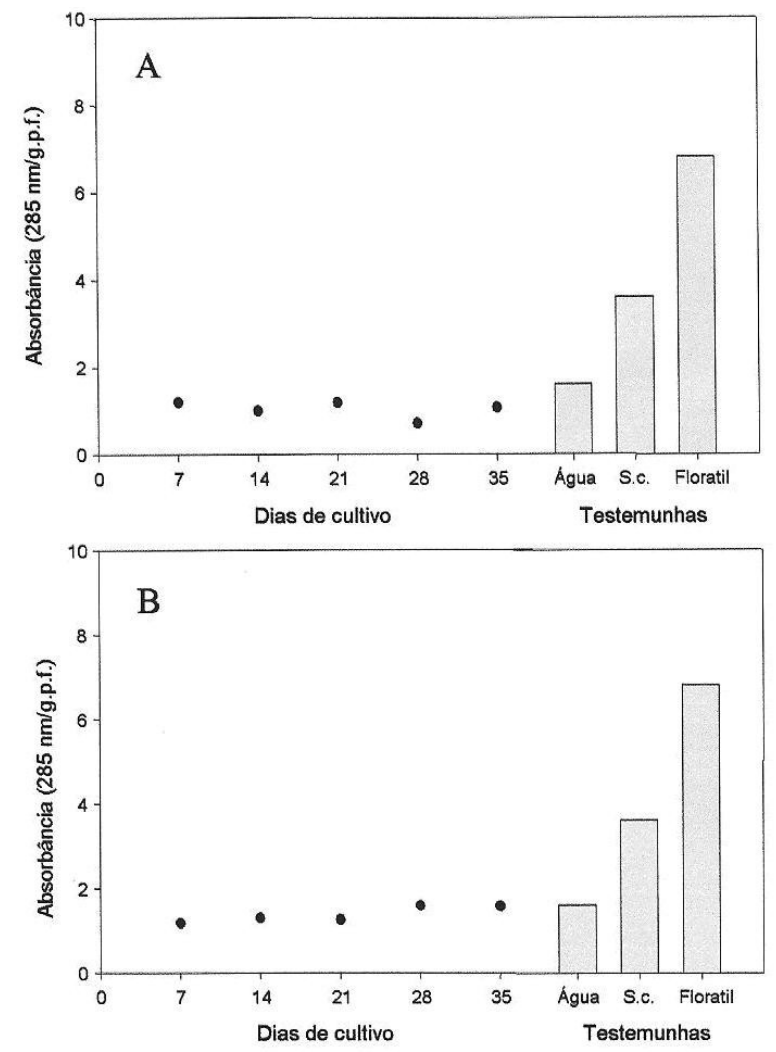

Fig. 2 - Produção de fitoalexinas em cotilédones de soja submetidos ao tratamento com suspensão de células de Saccharomyces boulardii cultivada por diferentes tempos em meio YEPG (A) e seus respectivos filtrados de cultura (B). As colunas representam os tratamentos controle água destilada e suspensão de células de S. cerevisiae (S.c.) (25 $\mathrm{mg} \mathrm{pc} / \mathrm{mL}$ ). Floratil: $25 \mathrm{mg}$ do produto comercial/mL; g.p.f. = grama de massa fresca.

Naliteraturanãohá relatos sobreousodeS.boulardii comoelicitor de respostas de defesa vegetal. Noentanto, há muitas citações com S. cerevisiae. Um exemploéo trabalho com cotilédones de soja tratados com sobrenadante de suspensão de células autoclavadas, sobrenadante da precipitação etanólica (EC) e resíduo sólido da precipitação etanólica de S. cerevisiae. Nesse trabalho o autor verificou que esses tratamentos proporcionaram indução de gliceolina, em média, cinco vezes maior que o tratamento controle com água destilada, alcançando valor máximo de absorbância da a 285nm deaproximadamente 1,6(LABANCA, 2002). Para EC a indução de gliceolina foi dose dependente ( $\mathrm{y}=$ $\left.0,0052 x+0,2237 ; R^{2}=0,9605\right)$. No entanto, esses preparadosnão foram capazes de proteger plantas de soja contra Microsphaera diffusa (oídio da soja).

Para sorgo, apenas filtradoe Floratil tiveram efeito dose dependente com equação de $1^{\circ}$ grau e $R^{2}$ de 0,63 e 0,94 respectivamente (Fig. 3). Para o filtrado de cultura, no entanto, a indução foi em média 20 vezes menor que a obtida com Floratil. Para este produto comercial a indução foi $94 \%$ maior que a obtida com ASM. Neste caso do sorgo, considerando-se que não houve efeito significativo da massa de células na indução de fitoalexinas, pode-se sugerir que o efeito elicitor do Floratil seja devido aos adjuvantes ou excipientes do produto comercial.
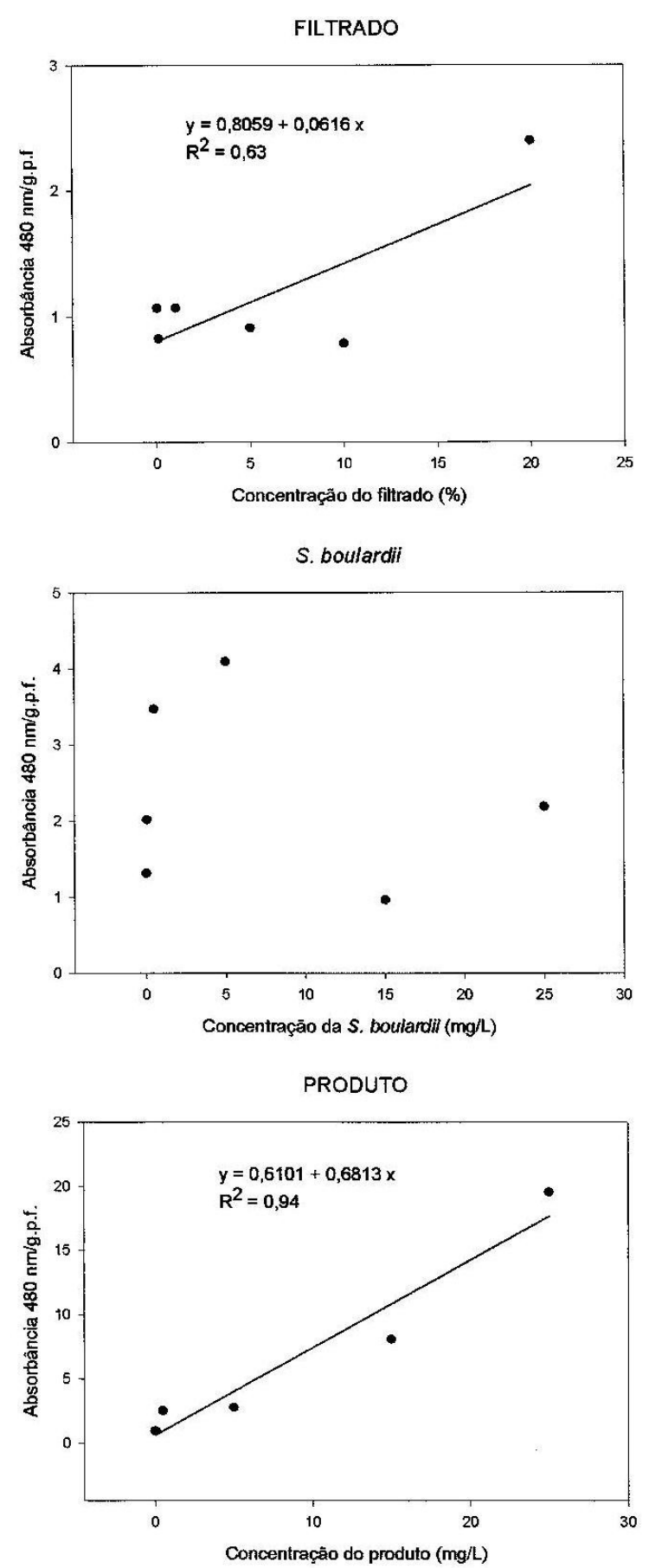

Fig. 3 - Produção de fitoalexinas em mesocótilos de sorgo submetidos ao tratamento com filtrado de cultura e suspensão de células de Saccharomyces boulardii e produto comercial Floratil. S. boulardii foi cultivada em meio YEPG; g.p.f. = grama de massa fresca. 
Quando se testam diferentes dias de cultivo, a massa de células de S. boulardii apresenta efeito dosedependente em sorgo (Fig. 4A), mas, no entanto, com valores praticamente semelhantes àqueles obtidos com o controle negativo água destilada.

Para ofiltrado, o efeito indutor em sorgo provavelmente seja devido a metabólitos que a levedura libera para o meio de cultura até os sete dias de cultivo ou enquanto as células ainda estão fisiologicamente ativas, já que com mais tempo de cultivo (Fig. 4B) não houve efeito significativo desse tratamentonaindução de fitoalexinas.
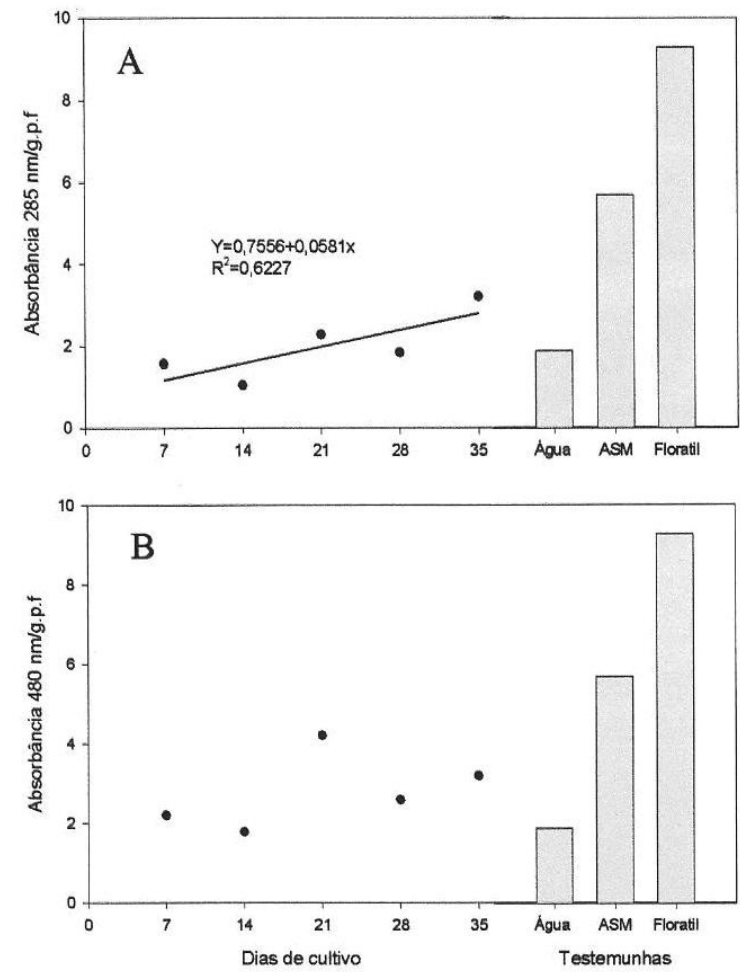

Fig. 4 - Produção de fitoalexinas em mesocótilos de sorgo submetidos ao tratamento com suspensão de células de Saccharomyces boulardii cultivada por diferentes tempos em meio YEPG (A) e seus respectivos filtrados de cultura (B). As colunas representam os tratamentos controle água destilada e acibenzolar-S-metil (ASM) (125 mg i.a./L). Floratil: $25 \mathrm{mg}$ do produto comercial $/ \mathrm{mL}$; g.p.f. = grama de massa fresca.

Pôde-se verificar que nem sempre a presença de células vivas de $S$. boulardii foi necessária para que ocorresse a indução das fitoalexinas em sorgo e, principalmente, em soja. Alguns trabalhos indicam o envolvimento de metabólitos e ou componentes derivados do gênero Saccharomyces em alterações no metabolismo de plantas tratadas com eles, exemplificado pela atividade de enzimas de defesa vegetal como peroxidase e fenilalanina amônia-liase e conteúdo de compostos fenólicos, como pode ser verificado a seguir.

Roncatto; Pascholati (1998) verificaram que a suspensão de células de S. cerevisiae $(25 \mathrm{mg} / \mathrm{mL})$ e seu respectivo filtrado, autoclavado ou não, alteraram a atividade e o padrão eletroforético de peroxidase em milho esorgo. Em sorgo, a atividade dessa enzima nas folhas foi maior em todos os tratamentos e intervalos detempo (24,48 e72h após os tratamentos) em relação ao controle água. Ainda em sorgo, as folhas tratadas com preparações dessa levedura evidenciaram a presença de três novas isoenzimas no tratamento com suspensão de células, quatro em suspensão autoclavada, três em filtrado autoclavado e duas em filtrado de suspensão autoclavada, concomitantemente ao desaparecimento de quatro, três, duas e quatro isoenzimas para esses tratamentos, respectivamente.

Por outrolado, KAmidaetal. (2000) não observaram nenhuma relação entre o tratamento com $S$. cerevisiae em tecidos de sorgo resistente e suscetível a Colletotrichum sublineolum e a expressão da enzima fenilalanina amônia-liase, indicando que a proteção dessas plantas a este patógeno pode ter envolvido outros mecanismos de defesa ou outros passos do metabolismofenólico.

Oacúmulodefitoalexinas foi observadoporWULF; Pascholati (1998) em mesocótilos de sorgo tratados com preparações de S. cerevisiae. Esses autores verificaram que a atividade elicitora é devido a moléculas de natureza termoestável e com efeito dependente da concentração proteica das amostras precipitadas com etanol 50\%. Além disso, esses elicitores adsorvem resina DEAE-celulose, apresentam massa molecular entre 18,4 e 25 kDa e a atividade biológica é reduzida apósotratamentocom proteinaseK(WuLfF; PASCHOLATI, 1999). Essa capacidade elicitora de derivados de $S$. cerevisiae também foi verificada por FreITASet al. (1993) e RoNCATTO; PASCHOLATI (1993), mas sem a caracterização da natureza química das moléculas elicitoras.

Em leveduras, particularmente S. cerevisiae, entre os polímeros presentes na parede celular e extraíveis com autoclavagem estão as $\beta$-glicanas e as manoproteínas, sendo estes últimos os únicos componentes de parede com natureza glicoproteica (CABIB et al., 1982). Embora neste trabalho as células de S. boulardii não tenham sido termotratadas, não se descarta a possibilidade da atividade elicitora ser devido a esses componentes da parede celular no tratamento dos cotilédones de soja com células da levedura, embora com alguma diferença estrutural, já que a indução com S. boulardii tenha sido sempre maior que a obtida com S. cerevisiae.

Os resultados encontrados com $S$. boulardii indicam o potencial dessa levedura e de derivados de 
cultura para trabalhos futuros, visando o controle de doenças em plantas por indução de resistência, em patossistemas envolvendo sorgo e soja, à semelhança do que já foi realizado com S. cerevisiae para controle da ferrugem do cafeeiro (MARTins et al., 1986), antracnose em milho (Silva; PAscholati, 1992), queima de Exserohilum em milho pipoca (STANGARLIN; Pascholati, 1994), antracnosee queima de Exserohilum em sorgo (Piccinin et al.,2005) e antracnose em pepino (LABANCA, 2002), não se descartando ainda a possibilidade de controle por atividade antimicrobiana direta (Stangarlin; Pascholati, 1994; Labanca, 2002; Bonaldo; Pascholati, 2007).

\section{CONCLUSÕES}

S. boulardii e derivados, como filtrado de cultura e produto comercial à base de células desta levedura, induzem a síntese das fitoalexinas gliceolina em soja e deoxiantocianidinas em sorgo.

\section{REFERENNCIAS}

BONALDO, S.M.; PASCHOLATI, S.F. Efeito de frações parcialmente purificadas de Saccharomyces cerevisiae na germinação de conídios e formação de apressórios por Colletotrichum sublineolum e Colletotrichum lagenarium. Summa Phytopathologica, v.33, n.3, p.233-238, 2007.

BRAGA, M.R. Fitoalexinas. In: PASCHOLATI, S.F.; LEITE, B.; STANGARLIN, J.R.; CIA, P. (Ed.). Interação Planta Patógeno - Fisiologia, bioquímica e biologia molecular. Piracicaba: FEALQ, 2008. p.305-346.

BURDEN, R.J.; BAILEY, J.A. structure of the phytoalexin from soybean. Phytochemistry, v.14, p.13891390, 1975.

CABIB, E.; ROBERTS, S.; BOWERS, B. Synthesis of the yeast cell wall and its regulation. Annual Review of Biochemistry, v.51, p.763-793, 1982.

CALVO, J.; CALVENTE, V.; DE ORELLANO, M.E.; BENUZZI, D.; DE TOSETTI, M. I.S. Improvement in the biocontrol of postharvest diseases of apples with the use of yeast mixtures. BioControl, v.48, n.5, p.579-593, 2003.

CAVALCANTI, L.S.; DI PIERO, R.M.; CIA, P.; PASCHOLATI, S.F.; RESENDE, M.L.V.; ROMEIRO, R.S. (Ed.). Indução de resistência em plantas a patógenos e insetos. Piracicaba: FEALQ, 2005. 263p.

COOK, R.J.; BAKER, K.F. The nature and practice of biological control of plant pathogens. St. Paul: APS Press, 1983. p.539.
DI PIERO, R.M.; GARCIA JUNIOR, D.; TONUCCI, N.M. Indutores bióticos. In: CAVALCANTI, L.S.; DI PIERO, R.M.; CIA, P.; PASCHOLATI, S.F.; RESENDE, M.L.V.; ROMEIRO, R.S. (Ed.). Indução de resistência em plantas a patógenos e insetos. Piracicaba: FEALQ, 2005. p.29-50.

El-TARABILY, K. A.; SIVASITHAMPARAM, K. Potential of yeasts as biocontrol agents of soil-borne fungal plant pathogens and as plant growth promoters. Mycoscience, v.47, n.1, p.25-35, 2006.

FREITAS, J.C.; ZARAMELLA, G.S.; PASCHOLATI, S.F. Efeito de agentes bióticos e abióticos no acúmulo de um complexo de pigmentos e fitoalexinas em mesocótilos de sorgo. Fitopatologia Brasileira, v.18, p.349, 1993. Suplemento.

GHINI, R.; KIMATI, H. Resistência de Fungos a Fungicidas. Jaguariúna: Embrapa Meio Ambiente, 2000. $78 \mathrm{p}$.

GOUVEA, A.; MAZZARO, S.M.; POSSENTI, J.C.; dos SANTOS, I.; STANGARLIN, J.R. Controle biológico de doenças em plantas pelo uso de leveduras. In: MARTIN, T.N.; MONTAGNER, M.M. (Ed.). Sistemas de produção agropecuária. Dois Vizinhos: Universidade Tecnológica Federal do Paraná, 2007. p.156-169.

KAMIDA, H.M.; PASCHOLATI, S.F.; BELLATO, C.M. Influência de Saccharomyces cerevisiae na expressão gênica da fenilalanina amônia-liase em tecido de sorgo protegido contra Colletotrichum sublineolum. Summa Phytopathologica, v.26, n.1, p.74-77, 2000.

LABANCA, E.R.G. Purificação parcial de elicitores presentes em Saccharomyces cerevisiae: atividade como indutores de resistência em pepino (Cucumis satious) contra Colletotrichum lagenarium e da síntese de gliceolina em soja. 2002. 118p. Dissertação (Mestrado) - Escola Superior de Agricultura "Luiz de Queiroz", Universidade de São Paulo, Piracicaba, 2002.

LOPEZ, A.M.Q. Controle alternativo da antracnose causada por Colletotrichum graminicola (Ces.) Wils. em sorgo (Sorghum bicolor L. Moench). 1991. 203p. Dissertação (Mestrado) - Universidade Estadual Paulista, Instituto de Biociências, Rio Claro, 1991.

MARTINS, E.M.F.; DE MARIA, A.C.; STOCKER, G.G.; MORAES, W.B.C. Changes in the resistance of detached coffee leaves by yeast extract filtrate and heat-treatment. Fitopatologia Brasileira, v.11, p.899-909, 1986.

MEINERZ, C.C.; FORMIGHIERI, A.P.; SCHWANESTRADA, K.R.F.; DIETERICH, C.; FRANZENER, G.; STANGARLIN, J.R. Atividade elicitora de fitoalexinas em sorgo e soja por derivados de avenca (Adiantum capillus-veneris L.). Revista Brasileira de Plantas Medicinais, v.10, n.2, p.26-31, 2008. 
MERCK. Floratil® - Saccharomyces boulardii-17 liofilizado. 2007.

MORAES, W.B.C. Controle alternativo de fitopatógenos. Pesquisa Agropecuária Brasileira, v.27. p.175-190, 1992.

NICHOLSON, R.L.; JAMIL, F.F.; SNYDER, B.A.; LUE, W.L.; HIPSKIND, J. Phytoalexin synthesis in the juvenile sorghum leaf. Physiological and Molecular Plant Pathology, v.33. p.271-278, 1988.

OSSWALD, W.; STANGARLIN, J.R.; NICHOLSON, R.L.; BRUMMER, M.; WULFF, N.A.; DI PIERO, R.M.; PICCININ, E.; DI CIERO, L.; HOTO, F.V.;

PASCHOLATI, S.F. The effect of acibenzolar-S-methyl on phytoalexin and PR-protein induction on sorghum mesocotyls and on Colletotrichum sublineolum. Summa Phytopathologica, v.30, p.415-420, 2004.

PASCHOLATI, S.F. Potencial de Saccharomyces cerevisiae e outros agentes bióticos na proteção de plantas contra patógenos. 1998. 123p. Tese (Livre-Docência) Escola Superior de Agricultura "Luiz de Queiroz", Universidade de São Paulo, Piracicaba, 1998.

PICCININ, E.; DI PIERO, R.M.; PASCHOLATI, S.F. Efeito de Saccharomyces cerevisiae na produtividade de sorgo e na severidade de doenças foliares no campo. Fitopatologia Brasileira, v,30, n.1, p.5-9, 2005.

POPIA, A.F.; CIDADE JUNIOR, H.A.; HAMMERSCHMIDT, I.; TOLEDO, M.V.; ASSIS, O. Manual de olericultura orgânica. Curitiba: Emater/Seab, 2007. 128p.

PUNJA, Z.K.; UTKHEDE, R.S. Using fungi and yeasts to manage vegetable crop diseases. Trends in Biotechnology, v.21, n.9, p.400-407, 2003.

RONCATTO, M.C.; PASCHOLATI, S.F. Mesocótilos estiolados de sorgo: bioensaio para a caracterização de frações de Saccharomyces cerevisiae envolvidas na proteção de plantas de sorgo contra fungos. In: REUNIÃO ANUAL DO INSTITUTO BIOLÓGICO, 6., 1993, São Paulo. Resumos. São Paulo: Instituto Biológico, 1993. p.31.

RONCATTO, M.C.; PASCHOLATI, S.F. Alterações na atividade e no perfil eletroforético da peroxidase em folhas de milho (Zea mays) e sorgo (Sorghum bicolor) tratadas com levedura (Saccharomyces cerevisiae). Scientia Agricola, v.55, n.3, p.395-402, 1998.

SCHWAN-ESTRADA, K.R.F.; STANGARLIN, J.R. Extratos e óleos essenciais de plantas medicinais na indução de resistência. In: CAVALCANTI, L.S.; DI PIERO, R.M.; CIA, P.; PASCHOLATI, S.F.; RESENDE,
M.L.V.; ROMEIRO, R.S. (Ed.). Indução de resistência em plantas a patógenos e insetos. Piracicaba: FEALQ, 2005. p.125-138.

SCHWAN-ESTRADA, K.R.F.; STANGARLIN, J.R.; PASCHOLATI, S.F. Mecanismos bioquímicos de defesa vegetal. In: PASCHOLATI, S.F.; LEITE, B.; STANGARLIN, J.R.; CIA, P. (Ed.). Interação planta patógeno - fisiologia, bioquímica e biologia molecular. Piracicaba: FEALQ, 2008. p.227-248.

SILVA, S.R.; PASCHOLATI, S.F. Saccharomyces cerevisiae protects maize plants, under greenhouse conditions, against Colletotrichum graminicola. Journal of Plant Disease and Protection, v.99, n.2, p.159-167, 1992.

STANGARLIN, J.R.; PASCHOLATI, S.F. Proteção de plântulas de milho pipoca contra Exserohilum turcicum pelo uso de Saccharomyces cerevisiae. Summa Phytopathologica, v.20, p.16-21, 1994.

STANGARLIN, J.R.; SCHWAN-ESTRADA, K.R.F.; CRUZ, M.E.S.; NOZAKI, M.H. Plantas medicinais e controle alternativo de fitopatógenos. Biotecnologia Ciência \& Desenvolvimento, n.11, p.16-21, 1999.

STANGARLIN, J.R.; KUHN, O.J.; SCHWAN-ESTRADA, K.R.F. Controle de doenças de plantas por extratos de origem vegetal. Revisão Anual de Patologia de Plantas, v.16, p.265-304, 2008.

VIECELLI, C.A.; STANGARLIN, J.R.; KUHN, O.J.; SCHWAN-ESTRADA, K.R.F. Indução de resistência em feijoeiro por filtrado de cultura de Pycnoporus sanguineus contra Pseudocercospora griseola. Tropical Plant Pathology, v.34, n.2, p.87-96, 2009.

VIGO, S.C.; FRANZENER, G.; STANGARLIN, J.R., SCHWAN-ESTRADA, K.R.F.; CRUZ, M.E.S. Indução de gliceolina em soja e inibição da germinação de conídios de Microsphaera diffusa pela tritura vegetal de Pfaffia glomerata. Fitopatologia Brasileira, v.26, p.351, 2001.Suplemento.

WULFF, N.A.; PASCHOLATI, S.F. Preparações de Saccharomyces cerevisiae elicitoras de fitoalexinas em mesocótilos de sorgo. Scientia Agricola, v.55, n.1, p. 138143, 1998.

WULFF, N.A.; PASCHOLATI, S.F. Partial characterization of sorghum phytoalexin elicitors isolated from Saccharomyces cerevisiae. Fitopatologia Brasileira, v.24, n.3, p.428-435, 1999.

Recebido em 13/1/09

Aceito em 21/10/09 